\title{
Morphometric measurements and animal-performance indices in a study of racial forms of Brazilian Sport Horses undergoing training for eventing
}

\author{
Felipe Gomes Ferreira Padilha', Agnaldo Machado de Andrade ${ }^{2}$, Ana Beatriz Monteiro \\ Fonseca ${ }^{3}$, Fernanda Nascimento de Godoi ${ }^{4}$, Fernando Queiroz de Almeida ${ }^{2}$, Ana Maria Reis \\ Ferreira $^{1^{*}}$
}

\footnotetext{
1 Universidade Federal Fluminense, Departamento de Patologia e Clínica Veterinária, Niterói, RJ, Brazil.

${ }^{2}$ Universidade Federal Rural do Rio de Janeiro, Seropédica, RJ, Brazil.

${ }^{3}$ Universidade Federal Fluminense, Departamento de Estatística, Niterói, RJ, Brazil.

${ }^{4}$ Universidade Federal da Bahia, Salvador, BA, Brazil.
}

\begin{abstract}
This study aimed to evaluate, in a practical manner, the use of linear and angular measurements and different animal-performance indices in a study on the breed-specific conformation of Brazilian Sport Horses training for eventing. These data can form the basis for the development of future studies based on the parameters evaluated and the calculations made. Seventeen Brazilian Sport Horses training for eventing were selected. Morphometric evaluations were made of all animals using linear and angular measurements. The linear measurements were withers, croup, and barrel heights; body, croup, shoulder, neck, and head lengths; head, chest, and hip widths; distance from the elbow to the ground and from the sternum to the ground (empty substernal); and thorax, forearm, knee, fetlock, and fore cannon girths. The angular measurements were shoulder-ground, shoulder-humerus, humerus-radius, metacarpus-phalanx, coxae-ground, coxae-femur, femur-tibia, and tibiametatarsus angles. Thirteen animal-performance indices were calculated to have a better understanding of the conformation of the animals and their proportions: the relationship between the withers and croup heights, chest index, dactyl-thoracic index, estimated weight, body index, thoracic index, conformation index, load index 1, load index 2, relative body index, compactness index 1, compactness index 2, and meloscopic index. Brazilian Sport Horses in eventing training were within the expected conformation for an athletic horse, but the animal-performance indices differed among them because they are heterogeneous horses resulting from crossing among various different breeds. The use of linear and angular measurements allows the correct characterization of racial forms of Brazilian Sport Horses undergoing training for eventing. Animal-performance indices can be useful in a study of a breed-specific conformation of athletic horses.
\end{abstract}

Key Words: angular measurements, conformation, equines, linear measurements

\section{Introduction}

The Brazilian Sport Horse breed began to appear in 1977, influenced by the English Thoroughbred, Hanoverian, Westphalian, Holsteiner, and Trakehner breeds, which contributed to its great genetic variability with an inbreeding coefficient close to zero (Dias et al., 2000).

The study on the breed-specific conformation of horses includes the calculation of linear and angular measurements

Received: April 2, 2016

Accepted: October 2, 2016

*Corresponding author: ana_ferreira@id.uff.br

http://dx.doi.org/10.1590/S1806-92902017000100005

How to cite: Padilha, F. G. F.; Andrade, A. M.; Fonseca, A. B. M.; Godoi, F. N.; Almeida, F. Q. and Ferreira, A. M. R. 2017. Morphometric measurements and animal-performance indices in a study of racial forms of Brazilian Sport Horses undergoing training for eventing. Revista Brasileira de Zootecnia 46(1):25-32

Copyright (C 2017 Sociedade Brasileira de Zootecnia. This is an Open Access article distributed under the terms of the Creative Commons Attribution License (http://creativecommons.org/licenses/by/4.0/), which permits unrestricted use, distribution, and reproduction in any medium, provided the original work is properly cited. and their proportions. The proportions are the relations between the different parts of the body of the animal and the associations they form. The proportions should be harmonious and the animal must be able to function as intended. To study these proportions, one must consider the linear and angular measurements, their continuity and general measurements, as well as any variations and compensations (Ribeiro, 1988).

Measuring the linear dimensions between various regions of the body allows a thorough assessment of the animal (Ribeiro, 1988; Torres and Jardim, 1981). The angular measurements are the relationships between the bone orientations. The open anterior angles, known as impellers, are strong and are related to the movements of the animal. Other angles (opening to the back) are called complementary or connection angles. As the angles are a function of the breed and type of horse according to the type of work/exercise for which the horse is intended, these angles vary among different horse breeds. For the animal to be harmonious, there must be a relative agreement between 
the openings of such angles. (Ribeiro, 1988; Torres and Jardim, 1981).

In the equestrian industry, selection is based on individual performance, pedigree, and phenotype. The physical conformation plays an important role in the phenotypic evaluation and is generally subjective and based on personal experience or opinion. However, little data are available on conformation and its relationship with performance and musculoskeletal disorders (Anderson and McIlwraith, 2004). Furthermore, Jönsson et al. (2014) stated that the standard conformations that experienced judges preferred were associated with the good health of the animal.

This study aimed to evaluate, in a practical manner, the use of linear and angular measurements and different animal-performance indices in an investigation on the breed-specific conformation of Brazilian Sport Horses training for eventing. These data can form the basis for the development of future studies based on the parameters evaluated and calculations made.

\section{Material and Methods}

The procedures of this study were approved by the Animal Use Ethics Committee (CEUA) of the Universidade Federal Fluminense (case no. 276/2013). The study was conducted on 17 Brazilian Sport Horses (Equus caballus) in Deodoro, Rio de Janeiro, Brazil. The horses (both male and female) were clinically healthy and were taking part in the eventing course of the Brazilian Army Riding School.

Morphometric evaluations were conducted by measuring the linear and angular dimensions of all animals. To obtain accurate measurements, each animal was placed in a forced stance with the fore and hind limbs perpendicular to a flat floor forming a rectangular parallelogram so that, seen in profile, each leg on one side obscured the leg on the opposite side; seen from the front or back, the legs were vertical and also on the floor (Figure 1).

A horse measuring stick, a tape measure, and an arthro-goniometer were used to measure 18 linear and eight angular dimensions according to Pinto et al. (2008) (Figure 2). The linear measurements were withers, croup, and barrel heights; body, croup, shoulder, neck, and head lengths; head, chest, and hip widths; distance from the elbow to the ground and from the sternum to the ground (substernal height); and thorax, forearm, knee, fetlock, and fore cannon girths. The angular measurements were shoulder-ground, shoulder-humerus, humerus-radius, metacarpus-phalanx, coxae-ground, coxae-femur, femur- tibia, and tibia-metatarsus. Finally, 13 animal-performance indices were calculated to obtain a better understanding of the conformation of the animals and their proportions based on the different linear measurements:

Relationship between height at withers and croup: height at the withers divided by croup height (McManus et al. 2005);

Chest index: relationship between the barrel and substernal height. The substernal height should be as close as possible to half the height of the horse (Ribeiro, 1988);

Dactyl-thoracic index: relationship between the fore cannon girth and thorax girth. This index cannot be less than 0.105 for small horses, 0.108 for riding horses, or 0.115 for large horses (Ribeiro, 1988);

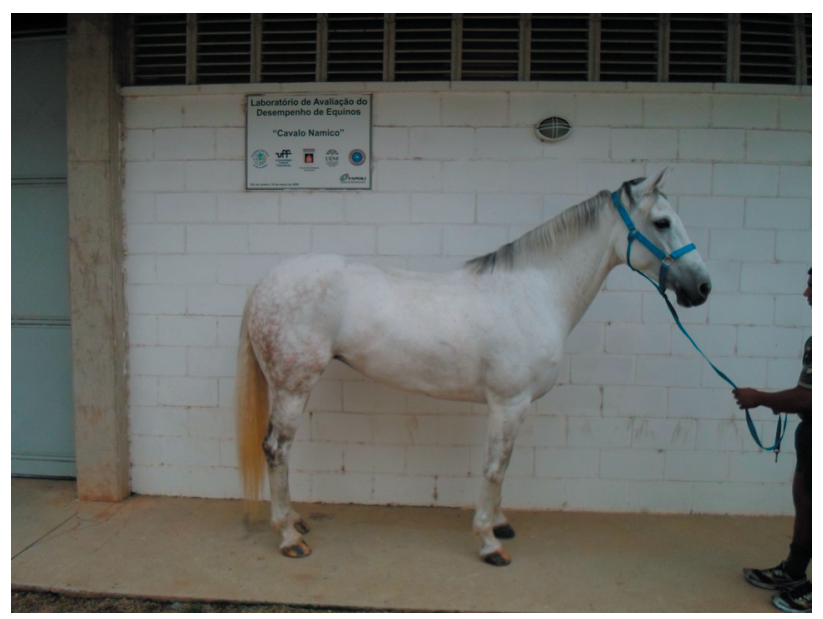

Figure 1 - Brazilian Sport Horse placed in a forced stance for morphometric evaluation.
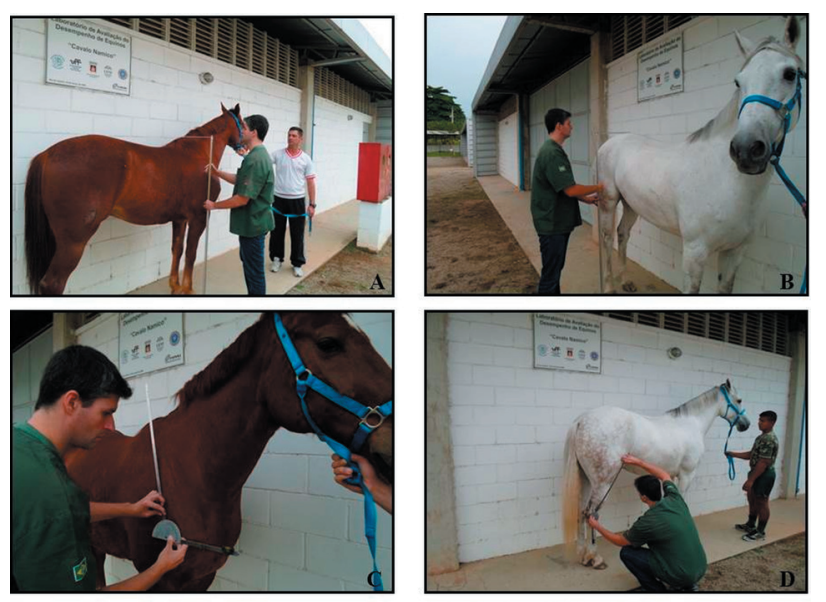

A - Height at the withers with the aid of a measuring stick; B - Height at croup with the aid of a measuring stick; $\mathrm{C}$ - shoulder-floor angle with the aid of an Arthro Goniometer; D - tibia-metatarsus angle with the aid of an Arthro Goniometer.

Figure 2 - Linear and angular measurements of Brazilian Sport Horses undergoing training for eventing. 
Estimated weight: cube of the thorax girth multiplied by the constant 80 . Weights $\geq 550 \mathrm{~kg}$, between 350 and $550 \mathrm{~kg}$, and $\leq 350 \mathrm{~kg}$ correspond to large horses (or those considered hypermetric), average sized horses (or medium), and small horses (or hypometric), respectively (Torres and Jardim, 1981);

Body index: relationship between body length and thoracic girth. A body index greater than 0.90 indicates that the animal is long; between 0.86 and 0.88 indicates that the animal is medium; less than 0.85 indicates that the animal is short. The long animal is best suited for speed, the short animal for strength, and the medium, with intermediate ratios, has intermediate abilities (Torres and Jardim, 1981);

Thoracic index: ratio between the width of the chest and height of the thorax. The thoracic index is $\leq 0.85$ for a long animal; between 0.85 and 0.90 for a medium animal; and $\geq 0.90$ for a short animal (Torres and Jardim, 1981);

Form index: thoracic girth squared and divided by the height of the withers. A riding horse must have a form index equal to 2.1125 , whereas values above this indicate that the animal is suitable for work (Torres and Jardim, 1981);

Load index 1: thoracic girth squared and multiplied by the constant 56 , divided by the withers height. The load index indicates the weight in kilograms the animal can withstand without excessive stress on the back, working at a trot or gallop (Torres and Jardim, 1981);

Load index 2: thoracic girth squared and multiplied by the constant 95 , divided by the withers height. This index indicates the weight in kilograms the animal can withstand without excessive stress on the back, working at a walking speed (Torres and Jardim, 1981);

Relative body index: body length multiplied by the constant 100 and divided by the withers height (Santos et al., 1995);

Compactness index 1: estimated weight divided by withers height, which is then divided by 100 . Heavy horses should have values greater than 3.15; values close to 2.75 indicate medium animals, and values near 2.60 indicate animals suitable for riding (light horses) (McManus et al., 2005);

Compactness index 2: estimated weight divided by the withers height minus 1 , which is then divided by 100 . This index also indicates the suitability of the animal. Values above 9.5 indicate animals for heavy work; between 8.0 and 9.5, animals for light work; and between 6.0 and 7.75, animals for riding (McManus et al., 2005);

Meloscopic index: This index is given by the relation among three circumferences measured at the middle of the forearm, at the knee, and at the shin and the height of the leg, i.e., the distance from the elbow to the ground. This index indicates whether the legs are well proportioned in relation to the trunk; when they are not, they indicate faulty gaits. The sum of the three circumferences should be lower (negative value), equal to (i.e., 0 ), or higher (positive value) than the height at the elbow in long, medium, and short horses, respectively (Torres and Jardim, 1981).

The SPSS software (Statistical Package for the Social Sciences, version 17) was used for all the descriptive statistics of the data analyzed and the correlations between the morphometric measurements and the animalperformance indices were based on Pearson's linear correlation coefficient and the corresponding significance test. Associations between parameters were analyzed using the Mann-Whitney $U$ test. In all analyses, the 5\% significance level was used.

\section{Results and Discussion}

The data obtained from the physical morphometric measurements of Brazilian Sport Horses in training for eventing (Tables 1 and 2) present some numerical differences compared with the findings of Souza (2013), who also evaluated horses of the same breed undergoing the same training with the following results (in $\mathrm{m}$ ): withers height, 1.55; croup height, 1.57; barrel height 0.67 ; body length, 1.58; croup length, 0.50; head length, 0.60; head width, 0.21 ; chest width, 0.41 ; and hip width 0.50 . These values are lower than those found in this study for the same

Table 1 - Individual linear measurements, means, standard deviations, and medians of Brazilian Sport Horses undergoing training for eventing

\begin{tabular}{lccc}
\hline & Mean $(\mathrm{m})$ & $\begin{array}{c}\text { Standard } \\
\text { deviation }(\mathrm{m})\end{array}$ & Median (m) \\
\hline Withers height & 1.62 & 0.034 & 1.62 \\
Croup height & 1.63 & 0.039 & 1.62 \\
Barrel height & 0.69 & 0.018 & 0.68 \\
Body length & 1.6 & 0.062 & 1.61 \\
Croup length & 0.52 & 0.026 & 0.51 \\
Shoulder length & 0.53 & 0.022 & 0.53 \\
Neck length & 0.68 & 0.042 & 0.68 \\
Head length & 0.63 & 0.021 & 0.63 \\
Head width & 0.22 & 0.012 & 0.22 \\
Chest width & 0.42 & 0.018 & 0.42 \\
Hip width & 0.54 & 0.018 & 0.55 \\
Distance from the elbow & 0.92 & 0.03 & 0.93 \\
to the ground & & & \\
Distance from the sternum & 0.86 & 0.019 & 0.86 \\
to the ground (empty substernal) & & & \\
Thorax girth & 1.84 & 0.041 & 1.84 \\
Forearm girth & 0.4 & 0.032 & 0.4 \\
Knee girth & 0.34 & 0.032 & 0.33 \\
Fetlock girth & 0.28 & 0.01 & 0.28 \\
Fore cannon girth & 0.2 & 0.01 & 0.2 \\
\hline
\end{tabular}


measurements, which were: $1.62,1.63,0.69,1.60,0.52$, $0.63,0.22,0.42$, and $0.54 \mathrm{~m}$, respectively. This difference indicates that the Brazilian Sport Horses selected for eventing training are becoming overall larger and these findings show that the characteristics of these animals are being modified for this sport as a result of selective breeding.

Our observation that sport horses in training for eventing are becoming larger is in contradiction with the data obtained for Crioulo horses in Brazil, which have shown a tendency to decrease their height over the generations (Kurtz Filho and Löf, 2007).

Warmblood horses studied by Catalano et al. (2016) presented higher mean values for withers height $(1.67 \mathrm{~m})$, body length $(1.79 \mathrm{~m})$, and thorax girth $(1.99 \mathrm{~m})$ compared with the Brazilian Sport Horses undergoing eventing training (1.62, 1.60, and $1.84 \mathrm{~m}$, respectively). It is important to emphasize that the origin of the Brazilian Sport Horse breed is mainly European warmbloods.

The horse described as having a downhill conformation (withers height lower than croup height) indicates that, in the exercise of their skills over generations, the best animals have such a conformation, even though, according to the literature, this is considered undesirable (Ribeiro, 1988).

Table 2 - Individual angular measurements, means, standard deviations, and medians of Brazilian Sport Horses undergoing training for eventing

\begin{tabular}{lccc}
\hline & Mean & $\begin{array}{c}\text { Standard } \\
\text { Deviation }\end{array}$ & Median \\
\hline Shoulder-floor angle & $70.82^{\circ}$ & $3.557^{\circ}$ & $70^{\circ}$ \\
Shoulder-humerus angle & $99.53^{\circ}$ & $5.58^{\circ}$ & $100^{\circ}$ \\
Humerus-radius angle & $145.41^{\circ}$ & $5.432^{\circ}$ & $145^{\circ}$ \\
Metacarpus-phalanx angle & $151.24^{\circ}$ & $6.17^{\circ}$ & $151^{\circ}$ \\
Coxae-ground angle & $27.06^{\circ}$ & $3.363^{\circ}$ & $26^{\circ}$ \\
Coxae-femur angle & $77.47^{\circ}$ & $5.535^{\circ}$ & $80^{\circ}$ \\
Femur-tibia angle & $109.18^{\circ}$ & $4.613^{\circ}$ & $108^{\circ}$ \\
Tibia-metatarsus angle & $147.18^{\circ}$ & $3.245^{\circ}$ & $148^{\circ}$ \\
\hline
\end{tabular}

This defect, as stated by Ribeiro (1988), is in fact a desired characteristic in Brazilian Sports Horses, corroborating the findings of this study. Stronger muscles in the hind limbs and taller hind limbs indicate greater power for jumping and ability to give a solo performance. This greater power is a desired trait in these horses. This feature was also found in Campeiro horses (McManus et al., 2005), in Brazilian Sport Horses and Thoroughbreds (Rezende et al., 2014), in horses from a mounted police squadron (Schade et al., 2015), and in Quarter Horses (Mariz et al., 2015).

Lucena et al. (2015) stated that the good performance of Marchador horses is influenced by the relation between withers height and croup height. Therefore, it is desirable that Campolina horses have a withers height higher than croup height, in contrast to the Brazilian Sport Horses of this study. Additionally, the proportions of the topline of Icelandic horses revealed an advantage of high withers and an uphill conformation, an important characteristic for riding ability in this five-gaited breed (Kristjansson et al., 2016).

The greatest chest width of the Brazilian Sport Horses in this study, compared with the findings of Souza (2013), indicates an increase in the ribcage and a tendency of a greater physical condition and respiratory ability of these horses.

Angeli et al. (2011) found highly positive significant correlations in Brazilian Sport Horses between withers height, croup height, body length, and knee-ground and hock-ground distances. A similar result was found in this study in horses of the same breed training for eventing in which correlations (Table 3) were found between withers height and croup height ( $\mathrm{IrI}=0.622 ; \mathrm{P}=0.008)$, withers height and substernal height ( $\mathrm{IrI}=0.625 ; \mathrm{P}=0.007)$, croup height and body length ( $\mathrm{IrI}=0.718 ; \mathrm{P}=0.001)$, and croup height and substernal height ( $\mathrm{IrI}=0.620 ; \mathrm{P}=0.008)$, as well as a trend between withers height and body length ( $\mathrm{IrI}=0.543 ; \mathrm{P}=0.024)$. Corroborating the findings of

Table 3 - Correlations and tendencies of correlations among linear measurements of Brazilian Sport Horses undergoing training for eventing

\begin{tabular}{|c|c|c|}
\hline Linear measurement & Correlation & Tendency \\
\hline Withers height & Croup height; empty substernal & Body length; head width \\
\hline Croup height & Body length; empty substernal & \\
\hline Body length & Head length; head width & \\
\hline Neck length & & Forearm girth \\
\hline Head length & & Head width; chest width \\
\hline Head width & Croup height & Thorax girth; fore cannon girth \\
\hline Hip width & Elbow to ground distance & Empty substernal \\
\hline Elbow to ground distance & Forearm girth & Empty substernal \\
\hline Knee girth & & Body length \\
\hline Fetlock girth & & Fore cannon girth; head length \\
\hline Fore cannon girth & Knee girth; fetlock girth & Head length; head width \\
\hline
\end{tabular}


this study in Brazilian Sport Horses, Lucena et al. (2015) found in Campolina horses a correlation $(\mathrm{P}<0.01)$ between withers height and croup height $(\mathrm{IrI}=0.712$ and $\operatorname{IrI}=$ 0.908 for geldings and stallions, respectively) and between withers height and body length (IrI $=0.737$ and $\mathrm{IrI}=0.718$ for geldings and stallions, respectively).

Correlations were also found between croup height and body length ( $\mathrm{IrI}=0.718 ; \mathrm{P}=0.001)$, croup height and substernal height ( $\mathrm{IrI}=0.620 ; \mathrm{P}=0.008)$, body length and head length ( $\operatorname{IrI}=0.615 ; \mathrm{P}=0.009)$ and width $(\mathrm{IrI}=0.693$; $\mathrm{P}=0.003)$, and head width and croup height $(\mathrm{IrI}=0.610$; $\mathrm{P}=0.012$ ). There were also tendencies of correlations between neck length and forearm girth $(\operatorname{IrI}=0.589$; $\mathrm{P}=0.013)$, head length and width $(\operatorname{IrI}=0.559 ; \mathrm{P}=0.024)$, head length and chest width ( $\mathrm{IrI}=0.566 ; \mathrm{P}=0.018)$, head width and thorax girth $(\mathrm{IrI}=0.567 ; \mathrm{P}=0.022)$, and fore cannon girth $(\mathrm{IrI}=0.588, \mathrm{P}=0.017)$.

Hip width demonstrated a correlation with the elbow to ground distance $(\mathrm{IrI}=0.616 ; \mathrm{P}=0.008)$ and a correlation tendency with substernal height $(\operatorname{IrI}=0.555 ; \mathrm{P}=0.021)$. The distance from the elbow to the ground was correlated with forearm girth $(\operatorname{IrI}=0.643 ; \mathrm{P}=0.005)$ and there was a correlation tendency with the substernal height $(\mathrm{IrI}=0.570$; $\mathrm{P}=0.017)$. A correlation tendency was found between knee girth and body length ( $\mathrm{IrI}=0.500 ; \mathrm{P}=0.041)$ and between head length and fetlock girth (IrI $=0.537 ; \mathrm{P}=0.026)$ and fore cannon girth $(\operatorname{IrI}=0.516, \mathrm{P}=0.034)$.

The fore cannon girth was correlated with the knee ( IrI $=0.610 ; \mathrm{P}=0.009)$ and fetlock $(\mathrm{IrI}=0.740 ; \mathrm{P}=0.001)$ girths and there was a correlation tendency between the fore cannon girth and the head length $(\operatorname{IrI}=0.516 ; \mathrm{P}=0.034)$ and width ( $\mathrm{IrI}=0.588 ; \mathrm{P}=0.017$ ).

Torres and Jardim (1981) reported that the horse must have joint angles suitable for its intended use. Thus, they established certain limits for the angles. Some average angles found in horses of this study were below those regarded as reference by these authors: shoulder-humerus angle, $99.53 \pm 5.58^{\circ}$ (reference: $102-115^{\circ}$ ); coxae-femur angle, $77.47 \pm 5.54^{\circ}$ (reference: $85-125^{\circ}$ ); femur-tibia angle, $109.18 \pm 4.61^{\circ}$ (reference: $122-150^{\circ}$ ); and tibia-metatarsus angle, $147.18 \pm 3.25^{\circ}$ (reference: $152-160^{\circ}$ ). The humerusradius angle $\left(145.41 \pm 5.43^{\circ}\right)$ and metacarpus-phalanx angle $\left(151.24 \pm 6.17^{\circ}\right)$ were within the limits set by these authors $\left(140-150^{\circ}\right.$ and $150-159^{\circ}$, respectively). These angles can be explained by the type of animal wanted and the sport for which it is intended. The authors probably based their data on the most common riding horses at the time, which were Mangalarga Marchador. This breed of horse presents a different way of walking, using a tri-pedal support style, unlike the trotting style of Brazilian Sport Horses. Furthermore, the Mangalarga Marchador horses are intended for light riding, unlike the Brazilian Sport Horse, which is intended for sport.

The shoulder-humerus angle was correlated with the distance from the elbow to the ground ( $\mathrm{IrI}=0.603 ; \mathrm{P}=$ $0.010)$ and a correlation was found between the metacarpusphalanx angle and barrel height $(\mathrm{IrI}=0.601 ; \mathrm{P}=0.011)$ and neck length ( $\mathrm{IrI}=0.607 ; \mathrm{P}=0.010$ ). The coxae-ground angle, in turn, was correlated with neck length $(\mathrm{IrI}=0.607$; $\mathrm{P}=0.010)$, coxae-femur angle ( $\operatorname{IrI}=0.727 ; \mathrm{P}=0.001)$, and tibia-metatarsus angle ( $\mathrm{IrI}=0.646 ; \mathrm{P}=0.005)$, and there was a correlation tendency with barrel height ( $\mathrm{IrI}=0.582$; $\mathrm{P}=0.014)$. The coxae-femur angle showed a correlation tendency with the femur-tibia angle $(\mathrm{IrI}=0.545 ; \mathrm{P}=0.024)$ and tibia-metatarsus angle ( $\operatorname{IrI}=0.527 ; \mathrm{P}=0.030)$ and the elbow to ground distance $(\mathrm{IrI}=0.566 ; \mathrm{P}=0.020)$ (Table 4).

Regarding the animal-performance indices, the average value of the relationship between withers height and croup height was $0.99 \pm 0.019$ and the conformation index had an average value of 2.1034 , which is near the value for a riding horse.

The average value for the estimated weight of the animals was $501 \pm 34.017 \mathrm{~kg}$, which characterizes a medium-sized animal. This result is in agreement with Godoi et al. (2013), who also classified such horses, in general, as medium. On the other hand, these authors classified Brazilian Sport Horse colts as large. Individually, in the present study, $88.2 \%$ of the animals $(\mathrm{n}=15)$ were classified as medium and $11.8 \%(n=2)$ as large or hypermetric animals.

The average value for the thoracic index was $0.62 \pm 0.025$, which indicates a long or sleek animal, and all of the individual horses $(100 \%$ or $n=17)$ were classified as sleek.

Table 4 - Correlations and correlation tendencies among angular and linear measurements of Brazilian Sport Horses undergoing training for eventing

\begin{tabular}{lll}
\hline Angular measurement & \multicolumn{1}{c}{ Correlation } & Tendency \\
\hline Shoulder-humerus angle & Distance from the elbow to the ground & \\
$\begin{array}{l}\text { Metacarpus-phalanx angle } \\
\text { Coxae-ground angle }\end{array}$ & Barrel height; neck length & \\
Coxae-femur angle & Neck length; coxae-femur angle; tibia metatarsus angle & Barrel height \\
& & Femur-tibia angle; tibia-metatarsus angle \\
\hline
\end{tabular}


The average value for the compactness index 1 was $3.104 \pm 0.187$, which indicates an animal capable of medium-to-light work. On evaluating the individual values, $58.8 \%$ of the horses $(\mathrm{n}=10)$ were grouped into the medium-to-light work category and $41.2 \%(n=7)$ into the heavy-work category. The average value for the compactness index 2 was $8.15 \pm 0.509$, again a value characterizing an animal capable of medium-to-light work. In the individual assessment, $82.4 \%(n=14)$ were categorized as capable of medium-to-light work and $17.3 \%(\mathrm{n}=3)$ as riding horses. The mean values of the compactness indices in Brazilian Sport Horses were consistent with the type of exercise to which the horses are subjected. In contrast, Lucena et al. (2016) found inconclusive results in Campolina horses, suggesting that more studies are needed to better classify this breed.

The average weight of the load index 2 was $199.83 \pm 7.85 \mathrm{~kg}$, i.e., the maximum weight carried by these animals without undue effort while walking. For load index 1, the maximum load without undue effort while working at a trot and gallop, the average weight was $117.79 \pm 4.63 \mathrm{~kg}$. Both indices had lower mean values compared with those found by Schade et al. (2015) in horses from a mounted police squadron $(210.51 \pm 13.97$ and $124.09 \pm 8.23 \mathrm{~kg}$, respectively).

The dactyl-thoracic index gave an average value of $0.111 \pm 0.01$, which classified the animals as riding horses. On evaluating the values individually, $47.1 \%$ of the animals $(\mathrm{n}=8)$ were classified as riding horses, $29.4 \%(\mathrm{n}=5)$ as heavy working horses, and $11.8 \%(\mathrm{n}=2)$ as small horses, and $11.8 \%(\mathrm{n}=2)$ were outside the range of this classification with values below 0.105 .

The chest index gave a mean value of $0.8 \pm 0.028$ and the relative body index was $98.87 \pm 3.25$. The average value for the body index $(0.87 \pm 0.035)$ classified the animals, in general, as medium-sized horses. Individually, $52.9 \%$ $(\mathrm{n}=9)$ were classified as medium, $23.5 \%(\mathrm{n}=4)$ as small, and $23.5 \%(\mathrm{n}=4)$ as sleek or long animals.

The meloscopic index showed that $58.8 \%(\mathrm{n}=10)$ of the animals were small, whereas $35.3 \%(n=6)$ were sleek and $5.9 \%$ were medium-sized $(n=1)$.
Associations were found among compactness index 1 and thorax girth $(\mathrm{P}=0.001)$, estimated weight $(\mathrm{P}=0.001)$, conformation index $(\mathrm{P}=0.001)$, compactness index 2 $(\mathrm{P}=0.002)$, and load indices $1(\mathrm{P}=0.001)$ and $2(\mathrm{P}=0.001)$. There was also an association between the dactyl-thoracic index and fore cannon girth $(\mathrm{P}=0.009)$ and an association tendency between the dactyl-thoracic index and head width $(\mathrm{P}=0.085)$ and knee $(\mathrm{P}=0.055)$ and fetlock $(\mathrm{P}=0.044)$ girths. The meloscopic index was associated with the knee $(\mathrm{P}=0.009)$ and fore cannon $(\mathrm{P}=0.020)$ girths, body index $(\mathrm{P}=0.028)$, and dactyl-thoracic ratio $(\mathrm{P}=0.005)$ and tended to be associated with body $(\mathrm{P}=0.044)$ and neck $(\mathrm{P}=0.044)$ lengths as well as the age of the animals $(\mathrm{P}=0.049)$ (Table 5).

In a literature review by the present authors, little was found concerning the ratio of angular measurements with respect to better performance in sports and the correlation of animal-performance indices with different characteristics of equine athletes, especially those within the scope of the present study. This observation was also made by Sole et al. (2014), who found a lack of correlation of morphological and functional variables in the equestrian sport of dressage.

Another factor worth highlighting is the heterogeneity of the animals of the Brazilian Sport Horse breed. As pointed out by Dias et al. (2000), this breed has been produced from various different breeds and, consequently, there is a large genetic variability. Thus, this genetic variability can explain the divergent phenotypic characteristics found by applying different formulas for the animal-performance indices in this study. The effect of breeding leading to differences in the phenotypic characteristics of horses was reported by Rezende et al. (2015).

The low rate of inbreeding in Brazilian Sport Horse was also observed in Lusitano horses, as mentioned by Vicente et al. (2014). However, these authors stated that this is detrimental to the evaluation of all morphological traits.

In the choice of animals for sports such as jumping, dressage, and eventing, height is taken into account; however, the most important factor is the actual performance

Table 5 - Associations and association tendencies among animal-performance indices and linear measurements of Brazilian Sport Horses undergoing training for eventing

\begin{tabular}{ll}
\hline Animal-performance index & \multicolumn{1}{c}{ Association } \\
\hline Compactness index 1 & $\begin{array}{l}\text { Thorax girth; estimated weight; conformation index; } \\
\text { compactness index 2; load index 1; load index 1 }\end{array}$ \\
Dactyl-thoracic index & Fore cannon girth \\
Meloscopic index & Knee girth; fore cannon girth; body index; dactyl-thoracic index $\quad$ Body length; neck length; age of the animals
\end{tabular}


of animals in competition, which was shown by Koenen et al. (1995). The authors claimed that, owing to correlations of genetics and reduced performance, indirect selection based on morphometrics has limited value.

Campos et al. (2007) evaluated the useful characteristics in the horse herd of the Brazilian Army, including Brazilian Sport Horses and mixed-breed horses, and claimed that selection by weight could obtain gains in height. However, that study was on animals during their growth stage, which is approximately from six to 48 months. In the present study, age was not taken into account, as they were all Brazilian Sport Horses aged between four and 10 years and were already at the end of their growth period.

Mangalarga Marchador horses are significantly influenced by age and environment, factors that, according to the authors, should be taken into consideration when choosing an animal based on angular and linear measurements (Lage et al., 2009). Miserani et al. (2002) cited the sub-regions (subtropical regions) and the year of registration as significant factors of variation. Because the Brazilian Sport Horses training for eventing, the heart of this study, were in the final stage of growth, age did not warrant much attention. In addition, they received the same kind of food and were exposed to similar environmental conditions. Therefore, such factors had little importance here.

A linear scoring system is able to generate quality information on different morphological traits (Sánchez et al., 2013). Duensing et al. (2016) affirmed that, based on comprehensive linear schemes for conformation and performance, it is possible to identify indicator traits that allow an efficient selection of a durable and competitive riding horse. Therefore, the study on morphometrics through linear and angular measurements and calculation of the various animal-performance indices enabled a deeper understanding of Brazilian Sports Horses in training for eventing. The determination of a more consolidated breedspecific conformation is still a step in the future, since the mixing of different breeds has resulted in great phenotypic heterogeneity as evidenced in this work.

\section{Conclusions}

The use of linear and angular measurements allows the correct characterization of racial forms of Brazilian Sport Horses undergoing training for eventing. Animalperformance indices can be useful in a study of a breedspecific conformation of athletic horses.

\section{Acknowledgments}

The authors thank Fundação Carlos Chagas Filho de Amparo à Pesquisa do Estado do Rio de Janeiro (FAPERJ) and Coordenação de Aperfeiçoamento de Pessoal de Nível Superior (CAPES).

\section{References}

Anderson, T. M. and McIlwraith, C. W. 2004. Longitudinal development of equine conformation from weanling to age 3 years in the Thoroughbred. Equine Veterinary Journal 36:563-570.

Angeli, A. L.; Reis, A. D. G.; Brusorio, D. R.; Simioni, L. C. and Hartmann, W. 2011. Biometria de cavalos da raça Brasileiro de Hipismo: resultados parciais. Revista eletrônica: Biociências, Biotecnologia e Saúde. Available at: <https://ayrtonsennabecalle. files.wordpress.com/2014/03/art_biometria_de.pdf $>$. Accessed on: Mar. 28, 2016.

Campos, V. A. L.; McManus, C.; Fuck, B. H.; Cassiano, L.; Pinto, B. F.; Braga, A.; Louvandini, H.; Dias, L. T. and Teixeira, R. A. 2007. Influência de fatores genéticos e ambientais sobre as características produtivas no rebanho equino do Exército Brasileiro. Revista Brasileira de Zootecnia 36:23-31.

Catalano, D. N.; Coleman, R. J.; Hathaway, M. R.; McCue, M. E.; Rendahl, A. K. and Martinson, K. L. 2016. Estimation of actual and ideal bodyweight using morphometric measurements and owner guessed bodyweight of adult draft and warmblood horses. Journal of Equine Veterinary Science 39:38-43.

Dias, I. M. G.; Bergmann, J. A. G.; Rezende, A. C. C. and Castro, G. H. F. 2000. Formação e estrutura populacional do equino Brasileiro de Hipismo. Arquivo Brasileiro de Medicina Veterinária e Zootecnia 52:647-654.

Duensing, J.; Stock, K. F. and Krieter, J. 2016. Implementation and prospects of linear profiling in the Warmblood horse. Journal of Equine Veterinary Science 34:360-368.

Godoi, F. N.; Bergmann, J. A. G.; Almeida, F. Q.; Santos, D. C. C.; Miranda, A. L. S.; Vasconcelos, F. O.; Oliveira, J. E. G.; Kaipper, R. R. and Andrade, A. M. 2013. Morfologia de potros da raça Brasileiro de Hipismo. Ciência Rural 43:736-742.

Koenen, E. P. C.; Van Veldhuizen, A. E. and Brascamp, E. W. 1995. Genetic parameters of linear scored conformation traits and their relation to dressage and show-jumping performance in the Dutch Warmblood Riding Horse population. Livestock Production Science 43:85-94.

Kristjansson, T.; Bjornsdottir, S.; Albertsdóttir, E.; Sigurdsson, A.; Pourcelot, P.; Crevier-Denoix, N. and Arnason, T. 2016. Association of conformation and riding ability in Icelandic horses. Livestock Science 189:91-101.

Kurtz Filho, M. and Löf, H. K. 2007. Biometria de equinos da raça Crioula no Brasil. Archives of Veterinary Science 12:47-51.

Jönsson, L.; Näsholm, A.; Roepstorff, L.; Egenvall, A.; Dalin, G. and Philipsson, J. 2014. Conformation traits and their genetic and phenotypic associations with health status in you Swedish warmblood riding horses. Livestock Science 163:12-25.

Lage, M. C. G. R.; Bergmann, J. A. G.; Procópio, A. M.; Pereira, J. C. C. and Biondini, J. 2009. Associação entre medidas lineares e angulares de equinos da raça Mangalarga Marchador. Arquivo Brasileiro de Medicina Veterinária e Zootecnia 61:968-979.

Lucena, J. E. C.; Vianna, S. A. B.; Berbari Neto, F.; Sales Filho, R. L. M. and Diniz, W. J. S. 2015. Estudo comparativo das proporções morfométricas entre garanhões e castrados da raça Campolina. Semina: Ciências Agrárias 36:353-366. 
Lucena, J. E. C.; Vianna, S. A. B.; Berbari Neto, F.; Sales Filho, R. L. M. and Diniz, W. J. S. 2016. Caracterização morfométrica de fêmeas, garanhões e castrados da raça Campolina baseada em índices. Arquivo Brasileiro de Medicina Veterinária e Zootecnia 68:431-438.

Mariz, T. M. A.; Santos, W. K.; Mota, L. F. M.; Martins, R. B.; Lima, C. B.; Escodro, P. B.; Lima Júnior, D. M.; Oliveira, L. P.; Sousa, M. F. and Ribeiro, J. S. 2015. Avaliação de medidas morfoestruturais em equinos da raça Quarto de Milha utilizando análises de imagens. Acta Veterinaria Brasilica 9:362-368.

McManus, C.; Falcão, R. A.; Spritze, A.; Costa, D.; Louvandini, H.; Dias, L. T.; Teixeira, R. A.; Rezende, M. J. M. and Garcia, J. A. S. 2005. Caracterização morfológica de equinos da raça Campeiro. Revista Brasileira de Zootecnia 34:1553-1562.

Miserani, M. G.; McManus, C.; Santos, S. A.; Silva, J. A.; Mariante, A. S. and Abreu, U. G. P. 2002. Avaliação dos fatores que influem nas medidas lineares do cavalo Pantaneiro. Revista Brasileira de Zootecnia 31:335-341.

Pinto, L. F. B.; Almeida, F. Q.; Quirino, C. R.; Azevedo, P. C. N.; Cabral, G. C.; Santos, E. M. and Corassa, A. 2008. Evaluation of the sexual dimorphism in Mangalarga Marchador horses using discriminant analysis. Livestock Science 119:161-166.

Rezende, M. P. G.; Abreu, U. G. P.; Souza, J. C.; Santos, S. A.; Ramires, G. G. and Sitorski, L. G. 2015. Morfologia corporal de equinos Quarto de Milha puros e mestiços utilizados no Laço Comprido no Mato Grosso do Sul. Archivos de Zootecnia 246:183-186.

Rezende, M. P. G.; Souza, J. C.; Mota, M. F.; Jardim, R. J. D.; Ramires, G. G.; Silva, R. M. and Souza, C. F. 2014. Morfometria corporal de equinos utilizados em trabalho, esporte e lazer em três municípios do Mato Grosso do Sul. Veterinária e Zootecnia 21:569-583.
Ribeiro, D. B. 1988. O cavalo de raças, qualidade e defeitos. Editora Globo Rural, Rio de Janeiro.

Sánchez, M. J.; Gómez, M. D.; Molina, A. and Valera, M. 2013. Genetic analyses for linear conformation traits in Pura Raza Español horses. Livestock Science 157:57-64.

Santos, S. A.; Mazza, M. C. M.; Sereno, J. R. B.; Abreu, J. R. B. and Silva, J. A. 1995. Avaliação e conservação do cavalo Pantaneiro. EMBRAPA-CPAC, Corumbá.

Schade, M. F. S.; Menegatti, J.; Schade, J.; Souza Júnior, V. A. and Fonteque, J. H. 2015. Avaliação morfométrica de equinos do Esquadrão de Polícia Montada dos municípios de Lages, Joinville e Florianópolis-SC. Arquivo Brasileiro de Medicina Veterinária e Zootecnia 67:1335-1342.

Sole, M.; Cervantes, I.; Gutierrez, J. P.; Gomez, M. D. and Valera, M. 2014. Estimation of genetic parameters for morphological and functional traits in a Menorca horse population. Spanish Journal of Agricultural Research 12:125-132.

Souza, B. G. 2013. Efeitos do exercício físico em esteira ergométrica de alta velocidade e do período de treinamento de equinos de Concurso Completo de Equitação: parâmetros morfológicos, metabólicos, bioquímicos e caracterização histoquímica e enzimohistoquímica do músculo glúteo médio. Tese (D.Sc.). Universidade Federal Fluminense, Niterói.

Torres, A. P. and Jardim, W. R. 1981. Criação do cavalo e de outros eqüinos. 3.ed. Nobel, São Paulo.

Vicente, A. A.; Carolino, N.; Ralão-Duarte, J. and Gama, L. T. 2014. Selection for morphology, gaits and functional traits in Lusitano horses: II. Fixed effects, genetic trends and selection in retrospect. Livestock Science 2014:13-25. 